\title{
Electrochemical Performance of Phyllanthus Muellerianus on the Corrosion of Concrete Steel-reinforcement in Industrial/Microbial Simulating-environment
}

\author{
Joshua O. Okeniyi, ${ }^{a, *}$ Cleophas A. Loto, ${ }^{a, b}$ Abimbola P. I. Popoola ${ }^{b}$ \\ ${ }^{a}$ Mechanical Engineering Department, Covenant University, Ota, Nigeria \\ ${ }^{b}$ Chemical, Metallurgical and Materials Engineering Department, Tshwane University of \\ Technology, Pretoria, South Africa
}

Received 22 February 2014; accepted 23 June 2014

\begin{abstract}
Electrochemical monitoring techniques were employed in this study to assess anticorrosion performance of Phyllanthus muellerianus leaf-extract on concrete steelreinforcement in $0.5 \mathrm{M} \mathrm{H}_{2} \mathrm{SO}_{4}$, used for simulating industrial/microbial environment. For this, steel-reinforced concretes admixed with different concentrations of the natural plant leaf-extract were partially immersed in the acidic test-solution and subjected to electrochemical monitoring of corrosion potential, corrosion current and corrosion rate. Test responses analysed as per ASTM G16-95 R04, showed that the corrosion rate correlated, $r=84.93 \%$, ANOVA $p$-value $=0.0403$, with the leaf-extract concentration admixed in concrete and the ratio of the standard deviation of potential to the standard deviation of current. These identified the $0.3333 \%$ Phyllanthus muellerianus (per weight of cement) with optimum effectiveness at inhibiting steel-reinforcement corrosion both by the experimental model, $\eta=91.66 \pm 2.51 \%$, and by the prediction from the correlation fitting model, $\eta=85.54 \pm 14.44 \%$. Fittings of both the experimental and the predicted data followed the Flory-Huggins and the Frumkin adsorption isotherms which suggest prevalent mechanism of physical adsorption (physisorption) of the extract on steel-rebar surface. These support the use of Phyllanthus muellerianus as environmentally-friendly admixture for inhibiting concrete steel-reinforcement corrosion in the industrial/microbial service-environment.
\end{abstract}

Keywords: steel-rebar corrosion in acidic environment; environmentally-friendly inhibitor; correlation fitting analysis; inhibition efficiency; adsorption isotherm.

\section{Introduction}

Corrosion of steel-reinforcement in concrete is a major problem affecting the structural integrity of building structures and infrastructures, for which steel-

\footnotetext{
* Corresponding author. E-mail address: joshua.okeniyi@ covenantuniversity.edu.ng
} 
reinforced concrete, due to its versatility, low cost and ease of manufacture, remained the material of choice globally [1-3]. Normally, steel reinforcement (steel-rebar) embedment in concrete is protected by a layer of thin oxide film in the highly alkaline concrete pore at $\mathrm{pH}>12$ [1,4-6]. However, aggressive acidifying agents of the environment lower $\mathrm{pH}$ in concrete, thereby breaking the passive oxide layer, and render concrete steel-rebar susceptible to corrosion degradation. Acidifying agents of the environment include sulphuric acid from acid rain and wastewater in industrial environments [3,7-9] and from sulphur reducing microbial activities in sewage environments [10-12]. Acidic sulphate from these sources attacks concrete, forms volume expansive products and an electrochemical cell of corroding steel-reinforcement that could eventually culminate, if unchecked, in the collapse of the steel-reinforced concrete structure $[3,5,11]$.

In many studies, the use of corrosion inhibitors as admixtures in concrete has been identified as an easy and effective technique for mitigating corrosion degradation of steel reinforced concrete in acidic sulphate environment [4,8$9,13]$. However, the chromate and nitrite based compounds that had been found as effective inhibitors of steel-rebar corrosion in these studies suffer the setbacks of limitation and restriction on the usage of the substances due to their toxicity and environmental hazardousness [14-16]. Apart from the toxicity and hazardousness to the environmental ecosystem, these inorganic, synthetic chemical inhibitors also hardly fulfil the important conditions of easy availability and cost effectiveness $[17,18]$. These necessitate search for environmentallyfriendly, easily available, cost effective and green alternatives for addressing the problems of corrosion degradation of steel reinforced concrete in the acidic sulphate environment.

Leaves of Phyllanthus muellerianus are traditionally employed for wound healing in Western Africa [19] and the extract from these leaves has been identified with antiplasmodial activity (suitability for treatment of malaria) and low toxicity in literature [20]. However, while leaf-extract of Phyllanthus amarus has been employed for inhibiting carbon steel corrosion in $\mathrm{Cl}^{-}$solution, no experiment has studied the inhibition effect of Phyllanthus muellerianus on concrete steel-reinforcement corrosion in acidic sulphate medium. This paper, therefore, studies the electrochemical performance of Phyllanthus muellerianus leaf-extract admixture on the corrosion of steel-reinforcement in concrete immersed in sulphuric-acid test-solution, for simulating industrial/microbial environment.

\section{Experimental}

\section{Preparation of Phyllanthus muellerianus leaf-extract}

Leaves of Phyllanthus muellerianus (P. muellerianus) Euphorbiaceae were dried under shade and blended into powder [21]. The blended powder was wrapped in a Whatman filter paper placed in a condenser equipped soxhlet extractor using methanol $\left(\mathrm{CH}_{3} \mathrm{OH}\right)$ as solvent [22] for obtaining the plant extract solution. This 
solution was then concentrated over water bath and the pasty remainder was used as inhibitor in the present study.

\section{Steel reinforced concrete samples}

Steel-reinforcement used in the study is of $12 \mathrm{~mm}$ diameter. This deformed steelrebar has the elemental composition: $0.273 \% \mathrm{C}, 0.780 \% \mathrm{Mn}, 0.403 \% \mathrm{Si}, 0.240 \%$ $\mathrm{Cu}, 0.142 \% \mathrm{Cr}, 0.109 \% \mathrm{Ni}, 0.039 \% \mathrm{P}, 0.037 \% \mathrm{~S}, 0.016 \% \mathrm{Mo}, 0.0086 \% \mathrm{Co}$, $0.0083 \% \mathrm{Nb}, 0.0063 \% \mathrm{Sn}, 0.0037 \% \mathrm{Ce}, 0.0032 \% \mathrm{~V}$ and the balance Fe. The rebar was cut into $190 \mathrm{~mm}$ steel rods for the corrosion experiment. Surface preparations for each of these rods were as per ASTM G109-99a [23], including surface grinding by different grades of abrasive paper, pickling in $10 \% \mathrm{H}_{2} \mathrm{SO}_{4}$, rinsing and cleaning in ultrasonic cleaner, degreasing in acetone and drying with warm air stream. $150 \mathrm{~mm}$ of each steel rod were centrally embedded in $100 \mathrm{~mm}$ $\times 100 \mathrm{~mm} \times 200 \mathrm{~mm}$ concrete slab, while the remaining $40 \mathrm{~mm}$ protrusion was used as connector for the electrochemical monitoring methods used in the study. This remaining protrusion of steel-rebar was painted with glossy paint after casting of each steel-reinforced concrete slabs.

Slabs of steel-reinforced concretes, having 0.5 water cement ratio [3], were cast in duplicates, according to the replication design suggested by Haynie [24], and for this, six concrete block duplicates were cast, with each duplicate admixed with similar $P$. muellerianus concentrations. These totalled twelve concrete block specimens. The duplicated samples were admixed with $P$. muellerianus leafextract concentrations that vary from $0 \%$, for the duplicated blank samples, in increments of $0.0833 \%$ (i.e., a part by weight of $P$. muellerianus in 1200 parts by weight of cement) up to $0.4167 \%$. These admixture designs in concrete block samples are presented in Table 1 and in this table it is shown that the duplicate sample for each concentration was tagged "(dup)".

Table 1. Admixtures of $P$. muellerianus leaf-extract in steel-reinforced concrete slabs.

\begin{tabular}{|c|c|c|c|}
\hline Specimen $\mathrm{N}^{\mathrm{o}}$ & Concentration of leaf-extract (wt \%) & Specimen $\mathrm{N}^{\circ}$ & Concentration of leaf-extract (wt \%) \\
\hline 1 & $0 \%$ P. muellerianus (Blank) & 2 & 0\% P. muellerianus (Blank(dup)) \\
\hline 3 & $0.0833 \%$ P. mиellerianus & 4 & $0.0833 \%$ P. mиellerianus(dup) \\
\hline 5 & $0.1667 \%$ P. muellerianus & 6 & $0.1667 \%$ P. muellerianus(dup) \\
\hline 7 & $0.25 \%$ P. mиеllerianus & 8 & $0.25 \%$ P. mиellerianus(dup) \\
\hline 9 & $0.3333 \%$ P. mиellerianus & 10 & $0.3333 \%$ P. mиellerianus(dup) \\
\hline 11 & $0.4167 \%$ P. mиellerianus & 12 & $0.4167 \%$ P. muellerianus(dup) \\
\hline
\end{tabular}

\section{Setup of corrosion test-samples}

The steel reinforced concretes for the electrochemical experiment were partially immersed, longitudinally, in plastic bowls containing $0.5 \mathrm{M} \mathrm{H}_{2} \mathrm{SO}_{4}$, as per standard procedures in studies for simulating industrial/microbial environment $[7,10]$. This corrosive test-solution was made up to just below the steel- 
reinforcement protrusion on the concrete but without touching the rebar, and was replenished to this level every three weeks for maintaining the corrosive environment $[15,25]$.

\section{Electrochemical monitoring experiment}

Measurements of corrosion test-data were obtained from the concrete samples first, in five days interval for 40 days and thereafter in seven days interval for the following four weeks (totalling 68-day experimental period), through use of electrochemical test-techniques [26-27]. The electrochemical test-techniques employed in the study include:

(1) Half-cell potential $(\mathrm{HCP})$ measurements versus $\mathrm{Cu} / \mathrm{CuSO} \mathrm{S}_{4}$ electrode $(\mathrm{CSE})$, Model 8-A, Tinker \& Rasor®, using a high impedance digital multimeter conforming to ASTM C876-91 R99 [5,13,27-28].

(2) Electrochemical cell current $(E C C)$ measurements, versus CSE using zero resistance ammeter (ZRA), Model ZM3P (Corrosion Service®) [29-31].

(3) Corrosion rate $(C R)$ measurements from linear polarization resistance using the three-electrode LPR Data Logger, Model MS1500L (Metal Samples®) [29]. This instrument which gave direct readout of $C R$ in mpy unit was connected, for measurements, to the steel-reinforced concrete specimen according to standard procedure in literature [15,26,29].

\section{Statistical analysis of measured corrosion test-data}

As per ASTM G16-95 R04 [32], measured corrosion test-data were subjected to the Normal and the Weibull distribution fittings to which the compatibility of the scatter of the test-data was also studied using the Kolmogorov-Smirnov goodness-of-fit (K-S GoF) statistics [33-34]. The expression for estimating the Normal mean, $\mu$, and the Normal standard deviation, $\sigma$, is well known. However, estimation of the Weibull shape $(k)$ and scale $(c)$ parameters, required for obtaining the Weibull mean, $\mu_{W}$, and standard deviation, $\sigma_{W}$, employed the combined fixed point iterative-Aitken $\Delta^{2}$ procedures [4] for solving the maximum likelihood equations:

$$
\begin{aligned}
& \frac{n}{\hat{k}}-n \ln (\hat{c})+\sum_{i=1}^{n} \ln x_{i}-\sum_{i=1}^{n}\left(\frac{x_{i}}{\hat{c}}\right)^{\hat{k}} \ln \left(\frac{x_{i}}{\hat{c}}\right)=0 \\
& \hat{c}-\left\{\frac{1}{n} \sum_{i=1}^{n} x_{i}^{\hat{k}}\right\}^{\frac{1}{\hat{k}}}=0
\end{aligned}
$$

So that the unbiased estimated values of $k$ and $c$ from Equation (1) and Equation (2) were then used for computing Weibull mean $\left(\mu_{W}\right)$ and standard deviation $\left(\sigma_{W}\right)$ from [13,35-37]:

$$
\mu_{W}=c \Gamma\left(1+\frac{1}{k}\right)
$$




$$
\sigma_{W}=\sqrt{c^{2}\left\{\Gamma\left(1+\frac{2}{k}\right)-\left[\Gamma\left(1+\frac{1}{k}\right)\right]^{2}\right\}}
$$

\section{Noise resistance $\left(R_{n}\right)$ modelling}

Requisite estimations, from the descriptive statistics exhibiting better compatibility with the scatter of the $H C P$ and the $E C C$ test-data were used for the ratio of the standard deviations of the corrosion potential and corrosion current, the noise resistance $\left(R_{n}\right)$ as [26-27,31,38-39]:

$$
R_{n}=\frac{\sigma_{H C P}}{\sigma_{E C C}}
$$

\section{Surface coverage and inhibition efficiency modelling}

In similar manner, requisite estimation from the descriptive statistics exhibiting better compatibility with the scatter of the $C R$ test-data were used for mean $C R$ values employed for surface coverage $(\theta)$ and inhibition efficiency $(\eta)$ modelling. These were obtained, for each admixed $P$. muellerianus concentration in concrete relative to the blank concrete sample, by $[15,17,29,40]$ :

$$
\begin{aligned}
& \theta=\frac{C R_{\text {Blank }}-C R_{\text {Admixed }}}{C R_{\text {Blank }}} \\
& \eta=\frac{C R_{\text {Blank }}-C R_{\text {Admixed }}}{C R_{\text {Blank }}} \times 100
\end{aligned}
$$

\section{Results and discussion}

\section{Test-results from the distribution fitting analysis of corrosion test-data}

The mean values of corrosion test-responses obtained from the statistical distribution fittings, by the Normal and by the Weibull distributions, of the measurements of corrosion test-data of $H C P, E C C$ and $C R$ were plotted in Fig. 1. The standard deviations from the mean values of the $H C P$ were included in Fig. 1(a) and of the ECC measurements were included in Fig. 1(b). Also, linear plots for directly interpreting corrosion risk as per ASTM C876-91 R99 [26-28] were included in Fig. 1(a), following the practice in Zamora et al. [5], and linear plot for directly interpreting corrosion rate, as classified in studies [41-42], was included in Fig. 1(c).

The plots in Fig. 1(a) and 1(b) showed that the concrete samples, especially the blank samples with $0 \mathrm{~g} P$. muellerianus admixtures, exhibited wide ranges of corrosion potential and corrosion current noise. The fluctuations in corrosion test-data readings responsible for this form of variations find similarities with fluctuations in corrosion potential measurements reported in other studies $[5,11,13,36-37]$. 


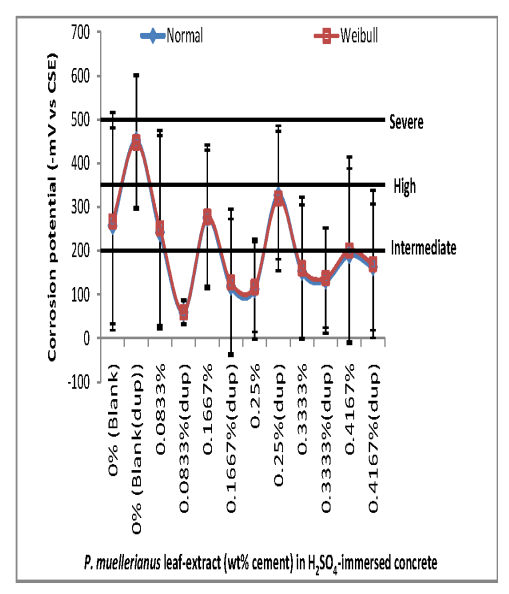

a)

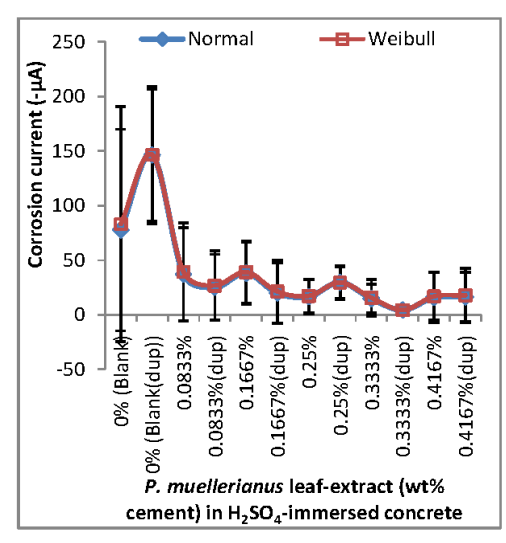

b)

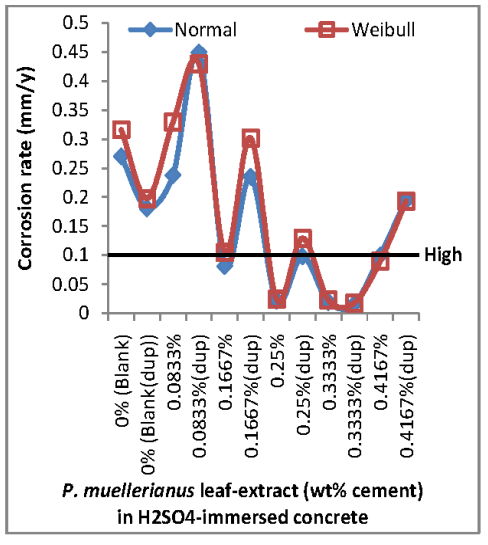

c)

Figure 1. Results of statistical distribution analysis of corrosion test-data: (a) mean and standard deviation ranges of $\mathrm{HCP}$ with plots of corrosion risks as per ASTM C876-91 R99 [28]; (b) mean values and standard deviation ranges of $E C C$; (c) corrosion rate $(C R)$ with plot of corrosion rate criteria as classified in studies [41-42]

Also, while similar pattern of Normal and Weibull mean values of $H C P$ and $E C C$ test-data could be observed in Fig. 1(a) and 1(b), the Weibull mean values of $C R$ in Fig. 1(c) exhibited many instances of over-predicting the Normal mean values of $C R$. The observable exception to this includes the duplicate (i.e. dup) sample of $0.0833 \%$ P. muellerianus and the $0.4167 \%$ P. muellerianus admixed sample that exhibited Normal mean values of $C R$ that over-predicted their Weibull mean values of $C R$. These discrepancies in mean value estimations, which could also be observed in the deviation ranges of the $H C P$ and the $E C C$, by the distribution functions necessitate ascertaining the statistics for describing the scatter of corrosion test-data as per ASTM G16-95 R04 [32].

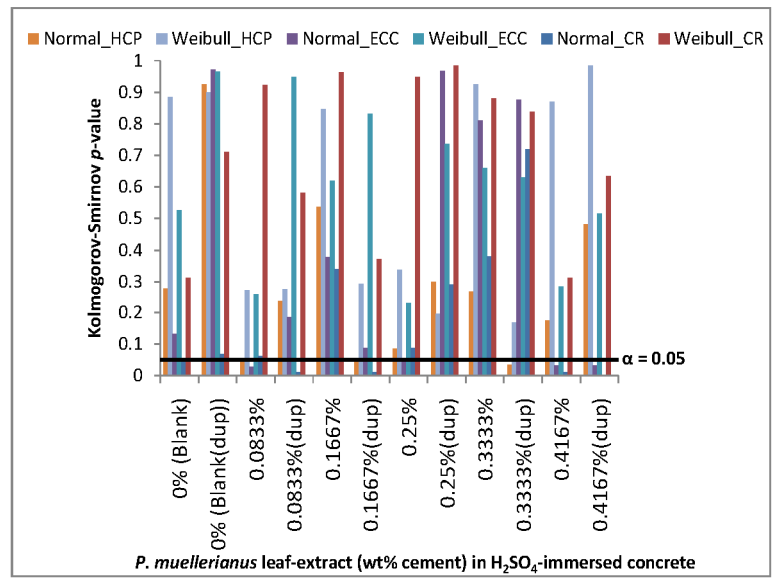

Figure 2. Goodness-of-fit test, by Kolmogorov-Smirnov statistics, of the scatter of corrosion test-data like the Normal and the Weibull distributions.

For this, the results of the goodness-of-fit test by the Kolmogorov-Smirnov statistics of the scatter of corrosion test-data like the Normal and Weibull distributions are shown in Fig. 2. Also shown in the figure was the linear plot of 
$\alpha=0.05$ for direct identification of the test-data scatter of corrosion test-variable that distributed like the Normal distribution and/or the Weibull distribution function. Thus, it could be identified from Fig. 2 that the scatter of the $H C P$ testdata of two samples, $E C C$ test-data of four samples and the $C R$ test-data of five samples, totalling eleven datasets of corrosion test-variables, were not distributed like the Normal distribution. The $p$-values of the Kolmogorov-Smirnov statistics for the Normal distribution fittings of these samples were less than 0.05 . According to ASTM G16-95 R04, using analysis of the techniques developed for the Normal distribution, e.g., mean and standard deviation evaluations, for the datasets of these test-data that distributed in another manner can lead to grossly erroneous conclusion. In contrast, Fig. 2 showed that the $p$-values of the Kolmogorov-Smirnov statistics for the Weibull distribution fittings of the testdata of corrosion test-variables for all the concrete samples in this study were greater than 0.05 . This implies that all the datasets of corrosion test-variables in the study distributed like the Weibull distribution, thus identifying the analysis techniques developed for the Weibull distribution as suitable for describing the corrosion test-data and for detailing $P$. muellerianus performance.

\section{Correlation fittings and analysis of corrosion rate and noise resistance}

By the scatter of the test-data of corrosion test-variable from all the samples like the Weibull distribution, the evaluation of the noise resistance, $R_{n}$ in Equation (5) , employed the ratio of the Weibull standard deviation of $H C P(\mathrm{mV})$ to the Weibull standard deviation of ECC (mA). Fig. 3 showed the plotting of the evaluations of this ratio, $R_{n}$, and the corrosion rate in ranking order of corrosion rate from the samples of steel-reinforced concrete immersed in the corrosive testmedium in the study. This figure generally showed that the sample with the higher-valued $R_{n}$ was attended with low corrosion rate, while the sample with the lower-valued $R_{n}$ exhibited high corrosion rate, which finds agreement with Kelly et al. [38] where $R_{n}$ values tracked linear polarisation resistance. These forms of results engender suggestions of the existence of relationship between the experimental data of corrosion rate and the noise resistance.

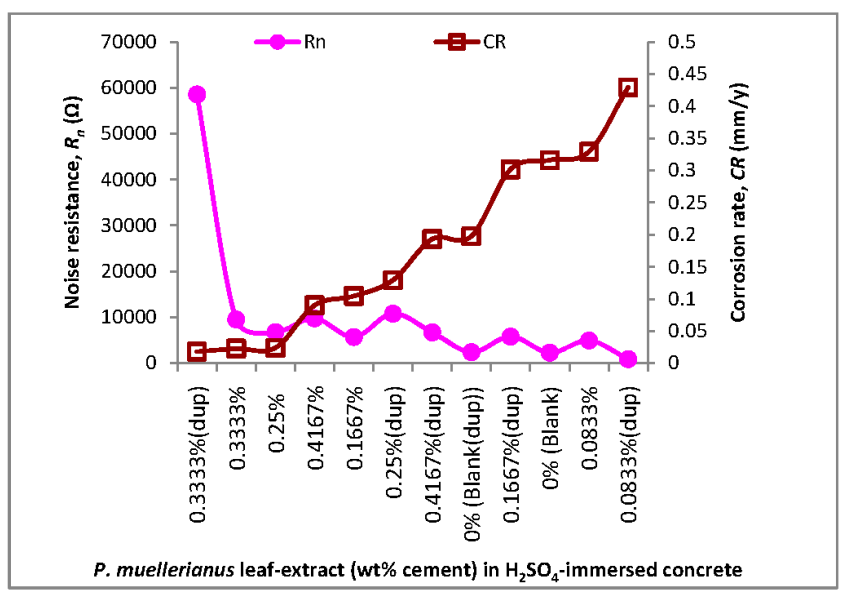

Figure 3. Plots of noise resistance and corrosion rate in ranking order of corrosion rate performance of $P$. muellerianus admixtures in concrete samples. 
Based on these, several correlation fitting model applications to the corrosion rate, $C R$, and the noise resistance, $R_{n}$, as well as the $P$. muellerianus leaf-extract concentration, $C$, were investigated before obtaining the relationship between these quantities in the form:

$$
C R=0.289+1.715 C\left\{C-5.832 \times 10^{-2}\left(1 / \log R_{n}^{0.595}\right)+3.665 \times 10^{3}\left(1 / R_{n}\right)-1.399 \times 10^{6}\left(1 / R_{n}^{2}\right)\right\}
$$

For the fitting performance of Eq.(8), the correlation coefficient, $r=84.93 \%$. The analysis of variance (ANOVA) of this fitting model, see Table 2, showed that the ANOVA $p$-value $=0.0403$ for the fitting model. This ANOVA $p$-value implies that it cannot be rejected that there is statistically significant relationship between the correlated dependent variable, $C R$, and the independent variables, $R_{n}$ and $C$ within $95 \%$ confidence interval.

Table 2. ANOVA for the correlation fitting model in Eq. (8).

\begin{tabular}{|c|c|c|c|c|c|}
\hline $\begin{array}{l}\text { Source of } \\
\text { variations }\end{array}$ & $d f$ & SS & MS & $F$ & $p$-value \\
\hline Regression & 4 & 0.1514 & 0.0379 & 4.5278 & 0.0403 \\
\hline Residual & 7 & 0.0585 & 0.0084 & & \\
\hline Total & 11 & 0.2099 & & & \\
\hline
\end{tabular}

\section{Inhibition efficiency and adsorption isotherm models}

Inhibition efficiency, from the use of Eq. (7) for the experimental $C R$ and the predicted $C R$ from the correlation fitting model, which were then averaged between the duplicate samples, are presented, in ranking order of $P$. muellerianus performance, in Fig. 4. The figure showed that though there were overpredictions by one model over the other, the experimental still agreed with the predicted model in effectiveness ranking of $P$. muellerianus performance at inhibiting steel-reinforcement corrosion in the acidic sulphate medium.

Both models identified the $0.3333 \%$ P. muellerianus leaf-extract concentration admixed in concrete with optimum inhibition efficiency performance, $\eta=$ $91.65 \pm 2.51$ (experimental) or $\eta=85.54 \pm 14.44$ (predicted) at inhibiting concrete steel-reinforcement corrosion. This was followed in experimental and predicted ranking order of effectiveness performance by the $0.25 \%$, the $0.4167 \%$ and the $0.1667 \%$ P. muellerianus admixture concentrations, that all exhibited positive effectiveness at inhibiting steel-rebar corrosion in the medium. However, the $0.0833 \%$ P. muellerianus admixture portrayed negative inhibition efficiency, $\eta=$ $-55.86 \pm 48.09 \%$ (experimental) or $-14.93 \pm 39.26 \%$ (predicted) which indicated that the admixture rather aggravated, rather than inhibited, steel-reinforcement corrosion. This bear suggestion of the $0.0833 \%$ P. muellerianus admixture as representing inadequate quantity of admixture concentration which studies $[41,43]$ posited as being potent with significantly intense corrosion attack rather corrosion inhibition in corrosive system. These constitute reasons the reported works in literature $[41,43]$ identified needs for the use of suitable concentration, 
i.e. sufficient quantity, of inhibitor for attaining effective corrosion inhibition and avoiding corrosion aggravation of steel-rebar in the requisite corrosive system.

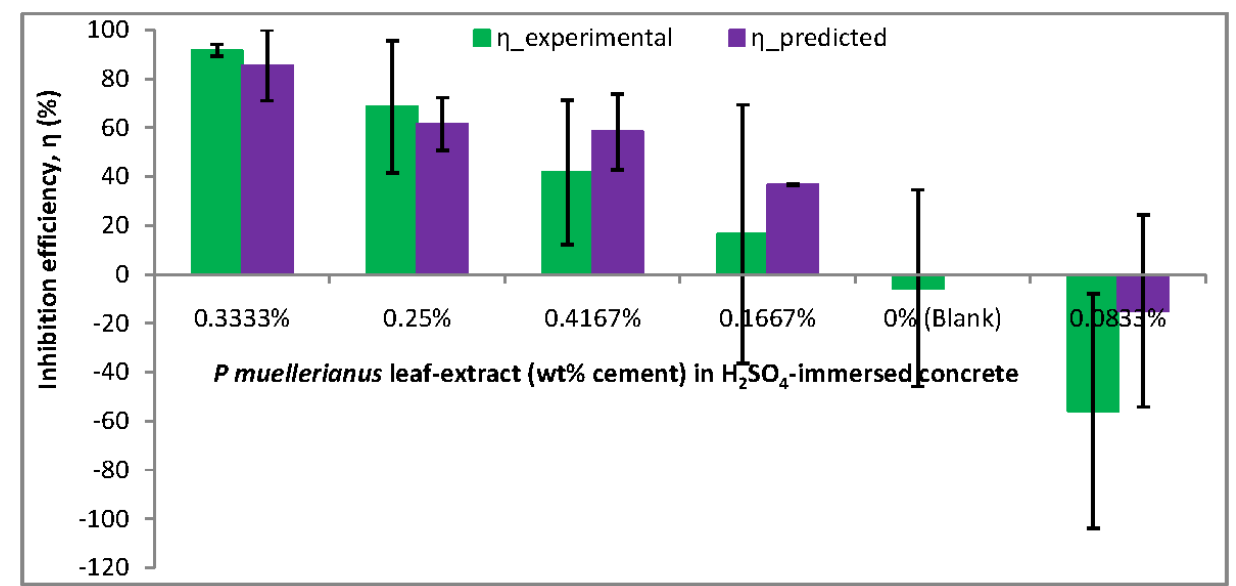

Figure 4. Inhibition efficiency performance of $P$. muellerianus leaf-extract on steel reinforcement corrosion.

The surface coverage, Equation (6), applied to the experimental and predicted models were subjected to different adsorption isotherms such as the Langmuir, Flory-Huggins, Frumkin and Freundlich isotherms. Among these, the experimental and predicted models followed the Flory-Huggins [44-45] and the Frumkin $[17,40]$ isotherms given respectively as:

$$
\begin{aligned}
& \log \left(\frac{\theta}{C_{0}}\right)=\log K_{F H}+n_{F H} \log (1-\theta) \\
& \log \left(\frac{\theta}{C(1-\theta)}\right)=2.303 \log K_{F r u m}+2 a \theta
\end{aligned}
$$

where $K_{F H}$ and $K_{F r u m}$ are, respectively, the equilibrium constants of the FloryHuggins and Frumkin desorption-adsorption process, $n_{F H}$ is the Flory-Huggins model exponent and $a$ is the Frumkin model of lateral interaction factor describing strength of attractive behaviour. Fig. 5 shows the plots of the FloryHuggins, Fig. 5(a), and of the Frumkin, Fig. 5(b), isotherm fittings of the experimental and the predicted models, while Table 3 presents important parameters estimated from the isotherm models. These parameters include estimation of the free energy of adsorption, $\Delta G_{a d s}^{o}$, using Gibbs-Helmotz equation $[17,45]$ :

$$
\Delta G_{a d s}^{o}=2.303 R T \log (55.5 K)
$$

The Flory-Huggins and the Frumkin fittings of adsorption isotherm were better correlated with the predicted model, for which respective correlation coefficient, $r_{F H}=96.57 \%$ and $r_{F r u m}=94.26 \%$, than with the experimental model for which, $r_{F H}=89.82 \%$ and $r_{\text {Frum }}=86.22 \%$. In spite of this, and the fact that the equilibrium constant from the Frumkin isotherm were slightly higher than that of 
the Flory-Huggins isotherm for both models, both fittings adsorption isotherms agreed in the negative $\Delta G_{a d s}^{o}$ that were greater than $-40 \mathrm{~kJ} / \mathrm{mol}$. The negative $\Delta G_{a d s}^{o}$ values suggest spontaneity of the adsorption process and stability of the adsorbed layer on the rebar surface, while greater than $-40 \mathrm{~kJ} / \mathrm{mol}$ values of $\Delta G_{a d s}^{o}$ in the modelled fittings indicated predominance of physical adsorption or physisorption [45]. The positive values of the lateral interaction factor, the Frumkin $a$-values in the experimental and the predicted models, bear indications that the adsorption energy is increased by the lateral attraction between the molecules in the adsorbed layer [40].

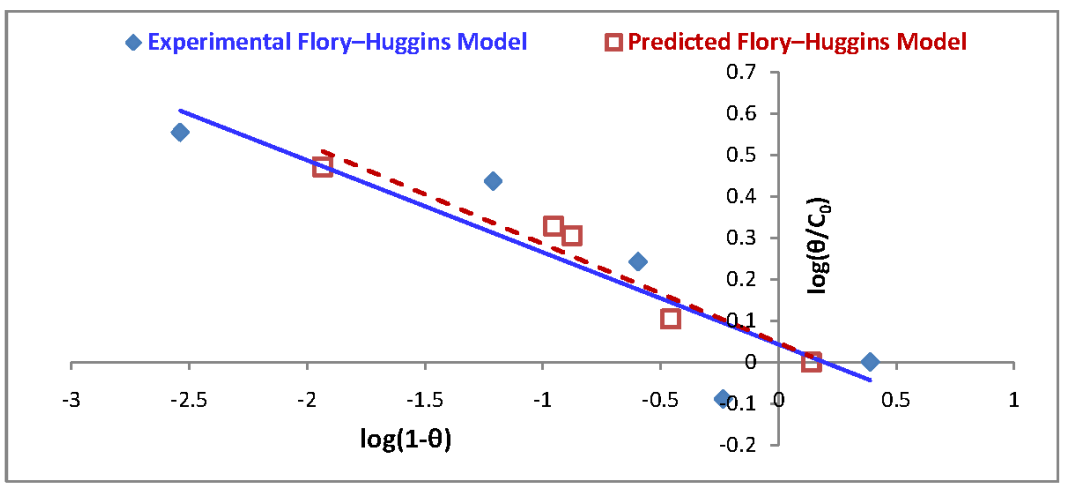

a)

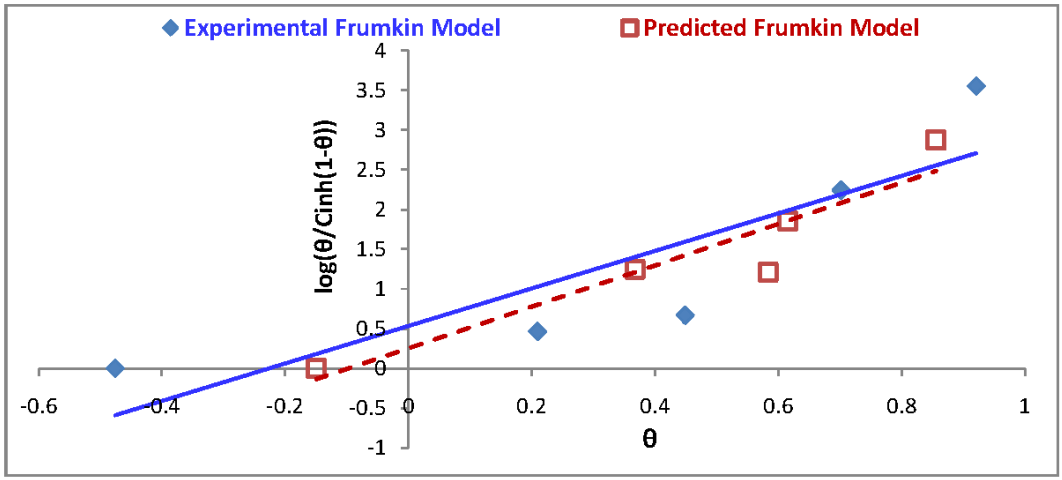

b)

Figure 5. Adsorption isotherm modelling of experimental and predicted performance of $P$. muellerianus on concrete steel-reinforcement in sulphuric-acid medium. (a) FloryHuggins isotherm model; (b) Frumkin isotherm model.

Table 3. Parameters estimated from the adsorption isotherm models of experimental and predicted data.

\begin{tabular}{|c|c|c|c|c|}
\hline \multirow{2}{*}{$\begin{array}{l}\text { Isotherm } \\
\text { parameter }\end{array}$} & \multicolumn{2}{|c|}{ Experimental model } & \multicolumn{2}{|c|}{ Predicted model } \\
\hline & Flory-Huggins & Frumkin & Flory-Huggins & Frumkin \\
\hline$K_{a d s}$ & 1.0439 & 1.2604 & 1.0477 & 1.1166 \\
\hline$r(\%)$ & 89.82 & 86.22 & 96.57 & 94.26 \\
\hline$a$ (interaction factor) & & 1.1817 & & 1.3032 \\
\hline$\Delta G_{a d s}(\mathrm{~kJ} / \mathrm{mol})$ & -23.3173 & -24.3999 & -23.3385 & -23.7041 \\
\hline
\end{tabular}

The results constitute reasons supporting the use of $P$. muellerianus leaf-extract as environmentally-friendly admixture for inhibiting reinforcing steel corrosion 
in steel-reinforced concrete designed for the microbial/industrial serviceenvironment.

\section{Conclusions}

Electrochemical techniques have been employed for studying the performance of $P$. muellerianus leaf-extract on the corrosion of concrete steel-reinforcement in $0.5 \mathrm{M} \mathrm{H}_{2} \mathrm{SO}_{4}$ simulating industrial/microbial environment. From this study, the following conclusions could be drawn:

- The Weibull distribution describes the scatter of corrosion test data better than the Normal distribution at $\alpha=0.05$ level of significance as per the KolmogorovSmirnov test-statistics, thus supporting the use of the Weibull distribution model for detailing admixture performance at inhibiting steel-reinforcement corrosion in the test-solution;

- The noise resistance tracks the corrosion rate from the linear polarisation resistance instrument in the present study environment and experimental conditions, whereby high noise resistance was attended with low corrosion rate, in agreement with what is obtained in literature;

- The corrosion rate of the concrete steel-reinforcement correlated with the function of the $P$. muellerianus leaf extract concentration admixed in concrete and the noise resistance, that is the ratio of the standard deviation of potential to the standard deviation of current are: (correlation coefficient $r=84.93 \%$; ANOVA $p$-value $=0.0403$ );

- The best inhibition efficiency at inhibiting the concrete steel-reinforcement corrosion was exhibited by the $0.3333 \%$ P. muellerianus leaf-extract admixture (per weight of cement), both from the experimental model where $\eta=$ $91.66 \pm 2.51 \%$, and from the predicted model from the correlation fitting where $\eta$ $=85.54 \pm 14.44 \%$;

- Adsorption isotherm modelling showed that the experimental and the predicted data followed the Flory-Huggins and the Frumkin models with respective correlation coefficient of $r_{F H}=89.82 \%$ and $r_{F r u m}=86.22 \%$ (experimental) and $r_{F H}=96.57 \%$ and $r_{F r u m}=94.26 \%$ (predicted) and both of which suggest the prevalent mechanism of physical adsorption (physisorption) of the extract on the steel-rebar surface;

- These experimental and predicted performances support, in agreement, the use of $P$. muellerianus leaf-extract admixture as an eco-friendly inhibitor of steelreinforcement corrosion in steel-reinforced concretes designed for the industrial/microbial service-environments.

\section{References}

1. Shi X, Xie N, Fortune K, et al. Construct Build Mater. 2012;30:125-138.

2. Reyna SLR, Vidales JMM, Tiburcio CG, et al. Port Electrochim Acta. 2010;28:153-164.

3. Baltazar MA, Almeraya-Calderon F, Carmona VO, et al. Port Electrochim Acta. 2004;22:335-344. 
4. Okeniyi JO, Oladele IO, Ambrose IJ, et al. J Cent South Univ. 2013;20:3697-3714.

5. Zamora MAB, Mendoza DN, Zamora HH, et al. Port Electrochim Acta. 2009;27:237-246.

6. Tam CT, Lim HB, Sisomphon K. The IES J Part A: Civ Struct Eng. 2008;1:146-153.

7. Gerengi H, Kocak Y, Jazdzewska A, et al. Construct Build Mater. 2013;49:471-477.

8. Tang Y, Zhang G, Zuo Y. Construct Build Mater. 2012;28:327-332.

9. Tommaselli MAG, Mariano NA, Kuri SE. Construct Build Mater. 2009;23:328-333.

10. Shing CK, Wu CML, Chen JWJ, et al. HKIE Trans. 2012;19:8-16.

11. Okeniyi JO, Omotosho OA, Ajayi OO, et al. Asian J Appl Sci. 2012;5:132143.

12. Wei S, Sanchez M, Trejo D, et al. Int Biodeterior Biodegrad. 2010;64:748754.

13. Okeniyi JO, Omotosho OA, Ajayi OO, et al. Construct Build Mater. 2014;50:448-456.

14. Shi JJ, Sun W. Cem Concr Compos. 2014;45:166-175.

15. Okeniyi JO, Omoniyi OM, Okpala SO, et al. Eur J Environ Civ Eng. 2013;17:398-416.

16. Fu JJ, Li SN, Cao LH, et al. J Mater Sci. 2010;45:979-986.

17. Eddy NO, Ameh PO, Gwarzo MY, et al. Port Electrochim Acta. 2013;31:79-93.

18. Johnsirani V, Sathiyabama J, Rajendran S, et al. Port Electrochim Acta. 2013;31:95-106.

19. Agyare C, Lechtenberg M, Deters A, et al. Phytomedicine. 2011;18:617624.

20. Zirihi GN, Mambu L, Guédé-Guina F, et al. J Ethnopharmacol. 2005;98:281-285.

21. Obi-Egbedi NO, Obot IB, Umoren SA. Arab J Chem. 2012;5:361-373.

22. Hameurlaine S, Gherraf N, Benmnine A, et al. J Chem Pharm Res. 2010;2:819-825.

23. ASTM G109-99a. Standard test method for determining the effects of chemical admixtures on the corrosion of embedded steel reinforcement in concrete exposed to chloride environments. West Conshohocken PA:ASTM International.

24. Haynie FH. In: Corrosion Tests and Standards: Application and Interpretation. 2nd Edition. Baboian R. (ed). West Conshohocken PA:ASTM International;2005. p. 83.

25. Muralidharan S, Saraswathy V, Nima SPM, et al. Mater Chem Phy. 2004;86:298-306.

26. Song HW, Saraswathy V. Int J Electrochem Sci. 2007;2:1-28.

27. Mendoza DN, Almeraya-Calderón F, Mejía JR, et al. Port Electrochim Acta. 2004;22:305-320. 
28. ASTM C876-91 R99. Standard test method for half-cell potentials of uncoated reinforcing steel in concrete. West Conshohocken PA:ASTM International.

29. Okeniyi JO, Ambrose IJ, Oladele IO, et al. Int J Electrochem Sci. 2013;8:10758-10771.

30. Sastri VS. Green Corrosion Inhibitors: Theory and Practice. Hoboken,New Jersey:John Wiley \& Sons Inc.;2011.

31. Eden DA. in Uhlig's Corrosion Handbook. 2nd Edition. Revie RW. (ed). New York:John Wiley \& Sons Inc.;2000. p. 1227.

32. ASTM G16-95 R04. Standard Guide for Applying Statistics to Analysis of Corrosion Data. West Conshohocken PA:ASTM International;2004.

33. Okeniyi JO, Okeniyi ET. J Stat Comput Simul. 2012;82:1727-1741.

34. Roberge PR. in ASM Handbook. Corrosion: Fundamentals, Testing, and Protection. Cramer SD, Covino Jr BS. (eds). Vol. 13A. Materials Park, OH:ASM International;2003. p. 425.

35. Ajayi OO, Fagbenle RO, Katende J, et al. Int J Energ Environ Eng. 2013;4:1-15.

36. Omotosho OA, Okeniyi JO, Ajayi OO, et al. Int $\mathbf{J}$ Environ Sci. 2012;2:2346-2359.

37. Omotosho OA, Loto CA, Ajayi OO, et al. Agric Eng Int: CIGR J. 2011;13:1-17.

38. Kelly RG, Inman ME, Hudson JL. in Electrochemical Noise Measurement for Corrosion Applications: ASTM STP 1277. Kearns JR, Scully JR, Roberge PR, (eds). West Conshohocken, PA:ASTM International;1996. p. 101.

39. Núñez-Jaquez RE, Gaona-Tiburcio C, Uruchurtu-Chavarin J. et al. Port Electrochim Acta. 2005;23:111-121.

40. Singh MR, Bhrara K, Singh G. Port Electrochim Acta. 2008;26:479-492.

41. Söylev TA, Richardson MG. Construct Build Mater. 2008;22:609-622.

42. Millard SG, Law D, Bungey JH, et al. NDT\&E Int. 2001;34:409-417.

43. Vaysburd AM, Emmons PH. Cem Concr Compos. 2004;26:255-263.

44. Foo KY, Hameed BH. Chem Eng J. 2010;156:2-10.

45. Eddy NO, Mamza PAP. Port Electrochim Acta. 2009;27:443-456. 